\title{
Experimental evaluation of HCFO-1233zd-E as HFC-245fa replacement in an Organic Rankine Cycle system for low temperature heat sources
}

\author{
Francisco Molés ${ }^{1, a}$, Joaquín Navarro-Esbría ${ }^{a}$ Bernardo Peris ${ }^{\mathrm{a}}$, \\ Adrián Mota-Babiloni ${ }^{\mathrm{a}, \mathrm{b}}$
}

${ }^{a}$ ISTENER Research Group. Department of Mechanical Engineering and Construction, Campus de Riu Sec s/n, University Jaume I, E12071, Castellón (Spain).

${ }^{\mathrm{b}}$ Departamento de Ingeniería Química y Nuclear, Universidad Politécnica de Valencia, Camino de Vera 14, Valencia (Spain).

\begin{abstract}
This work has conducted an experimental evaluation of the working fluid HCFO1233zd-E as HFC-245fa replacement in ORC systems for low temperature heat sources. An ORC module has been tested with both working fluids and different operating conditions. Due to the different densities of the working fluids, the mass flow rate for HCFO-1233zd-E is approximately $20 \%$ lower than for HFC-245fa. This causes thermal and electrical powers to be lower for HCFO-1233zd-E than for HFC-245fa. However, net electrical efficiency is similar for both working fluids ranging from 5\% to $9.7 \%$. Regarding the expander performance, various performance indicators are addressed. The expander isentropic performance has a maximum value of $75 \%$, with higher values for HCFO-1233zd-E than for HFC-245fa. The overall efficiency of the expander, similar for both working fluids, ranges from $44 \%$ to $57 \%$.
\end{abstract}

Keywords: low GWP fluids; HFC-245fa; Organic Rankine Cycle; low temperature heat sources; experimental evaluation.

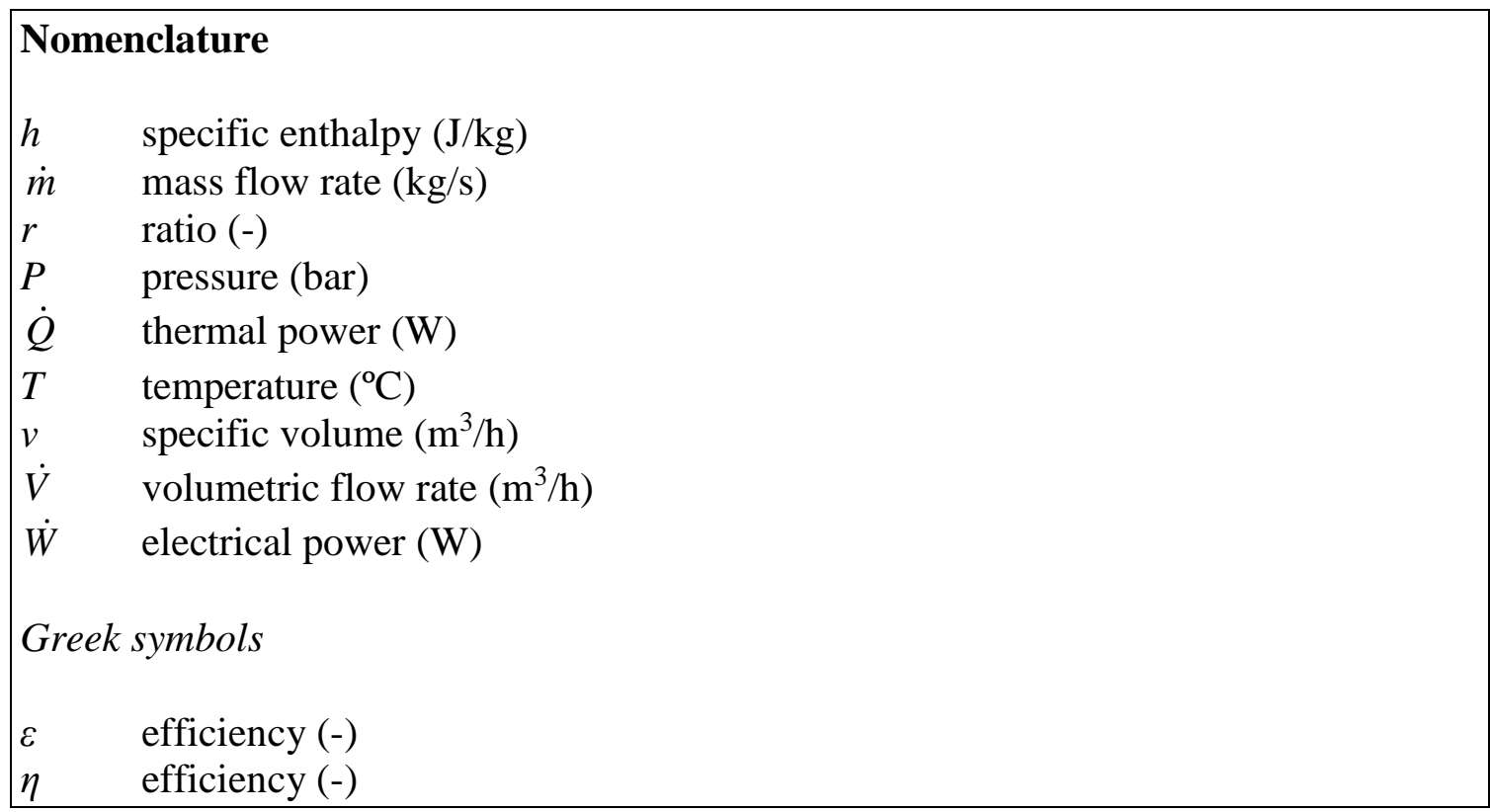

${ }^{1}$ Corresponding Author:

Tel: +34 964387529; fax: +34964728106.

E-mail address: molesf@uji.es 
\begin{tabular}{|ll|}
\hline$\rho$ & density $\left(\mathrm{kg} / \mathrm{m}^{3}\right)$ \\
$\varphi$ & filling factor $(-)$ \\
Subscripts \\
cond & condensation \\
evap & evaporation \\
exp & expander \\
i & in \\
in & internal \\
is & isentropic \\
n & net \\
o & out \\
oil & thermal oil \\
ov & overall \\
p & pressure \\
pp & pump \\
w & water \\
wf & working fluid \\
& \\
Acronyms \\
CHP & Combined Heat and Power \\
GWP & Global Warming Potential \\
HCFO HydroChloroFluoroOlefin \\
HFC & HydroFluoroCarbon \\
ODP & Ozone Depletion Potential \\
ORC & Organic Rankine Cycle \\
& \\
\hline
\end{tabular}

\section{Introduction}

Due to environmental constrains, the Organic Rankine Cycle (ORC) has been attracting increasing attention over the past decades. Unlike the traditional steam Rankine cycle, it uses an organic substance as working fluid instead of water, being able to work with low temperature heat sources in both power and Combined Heat and Power (CHP) applications [1]. Several ORC systems have been installed for recovering waste heat from cement [2] or oil industry [3] operations or from internal combustion engines [4]. ORC systems have also been widely used for converting renewable energy, such as solar [5], biomass [6] and geothermal [7], energy into power.

The choice of the ORC working fluid has an important influence on the system efficiency. Shale et al. [8] and Shengjun et al. [9] evaluated various working fluids for low temperature applications, highlighting that hydrocarbons with low critical temperatures, such as HFC-134a and HFC-245fa, are suitable. Moreover Quoilin et al. [10] highlighted that HFC-245fa is a common working fluid in commercial ORC installations, mainly used in waste heat recovery from low temperature heat sources. Additionally they observed that, at the present time, most commercial ORC plants exhibit a simple architecture: sub-critical working conditions, single-component working fluids, single evaporation pressure, and possible use of a recuperator heat 
exchanger. Regarding expansion technology, Peris et al. [11] indicates that the volumetric expander type is most appropriate for low grade heat sources and small scale applications.

So, various experimental studies have been carried out in the literature with ORC systems with the previous mentioned characteristics for low temperature heat sources. Bracco et al. [12] tested a small-size ORC prototype using HFC-245fa as working fluid and a scroll volumetric expander achieving a net cycle electrical efficiency around $8 \%$ and a gross electrical power of $1.5 \mathrm{~kW}$. Declaye et al. [13] characterized an oil-free scroll volumetric expander using HFC-245fa as working fluid, showing that the cycle could produce up to $50^{\circ} \mathrm{C}$ of useful heat and a maximum shaft power and cycle efficiency of $2.1 \mathrm{~kW}$ and $8.5 \%$, respectively. Peris et al. [14] characterized experimentally an ORC for micro-scale CHP applications, achieving a maximum electrical net power of $5.6 \mathrm{~kW}$ and a maximum net electrical efficiency of $8.8 \%$.

Attending to environmental issues, HFC-245fa is a hydrofluorocarbon (HFC) with zero Ozone Depletion Potential (ODP). However, the environmental impact of a working fluid, when it escapes to the atmosphere, is not limited to stratospheric ozone layer depletion. In fact, while all HFCs are harmless to the earth's stratospheric ozone layer, some HFCs with large Global Warming Potential (GWP) could contribute significantly to climate change. HFCs were designated as greenhouse gases under the Kyoto Protocol in 1997 [15] and they are currently targeted by efforts to reduce greenhouse gas in most developed countries. As a result, alternatives are sought for high GWP HFCs, such as HFC-245fa, which has a GWP of 858 [16]. HCFO-1233zd-E, a hydrochlorofluoroolefin (HCFO) with a GWP of 1 [16], has been proposed as a low GWP alternative to replace HFC-245fa in various applications, including ORC systems [17]. Despite the presence of chlorine in the molecule of HCFO-1233zd-E some studies have concluded that its ODP is an extremely small value (of 0.00034) due to its very short atmospheric lifetime [18]. Molés et al. [19] studied theoretically the performance of ORC systems using HCFO-1233zd-E as alternative to HFC-245fa for low temperature heat sources, concluding that this working fluid is predicted to have attractive performance, where the efficiency is benefitted substantially by the use of a recuperator.

In the present work an experimental evaluation of HCFO-1233zd-E as HFC-245fa replacement in ORC systems for low temperature heat sources is carried out. The rest of the paper is organized as follows: Section 2 describes the experimental setup; Section 3 presents the experimental procedure and data validation; Section 4 reports and discusses the main results; finally, Section 5 summarizes the main conclusions.

\section{Experimental setup}

The experimental tests are carried out in a monitored test bench that consists of a commercial ORC module [20] using HFC-245fa and HCFO-1233zd-E as working fluids. This ORC uses a regenerative configuration, shown in Fig. 1, that allows not only recovering the thermal energy from the heat source, but also the waste heat from the expander outlet, improving the cycle electrical efficiency. Other features of the commercial ORC module are listed in Table 1. 
Fig. 1. Regenerative configuration.

Table 1. Commercial ORC module features.

The test bench is completed with two secondary circuits, a heat sink water loop and a heat source thermal oil loop. The heat sink water loop consists of a closed-type cooling system, which allows controlling the temperature of the water. The heat source thermal oil loop is composed by an electrical boiler, which allows controlling the temperature of the thermal oil.

The thermodynamic states of the working fluid are calculated using REFPROP [21] measuring pressure and temperature at the inlet and outlet of each bases component of the test facility, using K-type thermocouples and piezoelectric pressure gauges. The working fluid mass flow rate is measured by means of a coriolis effect mass flow meter, the heat sink water loop volumetric flow rate is measured with an electromagnetic flow meter and the heat source thermal oil loop volumetric flow rate is measured with a vortex meter. The electrical power generated by the expander and the electrical power consumed by the pump are obtained with two digital wattmeters. Finally, all the measurements are gathered with a data acquisition system and monitored through a personal computer.

In Table 2 a summary of the measured parameters and the sensors used in this work is presented, indicating the uncertainty associated with each measurement.

Table 2. Measured parameters and equipment uncertainty.

\section{Experimental procedure and data validation}

\subsection{Experimental steady-state tests}

In order to be able to evaluate the working fluid HCFO-1233zd-E as HFC-245fa replacement, the commercial ORC module has been tested with both working fluids in the operating range expected in its usual performance. So, the water inlet temperature has been set in three different values, while the water and thermal oil volumetric flow rates have been kept constant. The thermal oil inlet temperature has been varied from about $140^{\circ} \mathrm{C}$ to more than $155^{\circ} \mathrm{C}$. The superheating at the expander inlet has been maintained constant at $25^{\circ} \mathrm{C}$. The experimental data consist of 160 steady-state tests, which are represented in Fig. 2, obtained in a wide range of operating conditions, as shown in Table 3, which have been used to characterize the energy performance of the facility using both working fluids.

Fig. 2. Thermal oil and water inlet temperatures obtained during steady-state tests. 
Table 3. Range of operating conditions in the experimental steady-state tests.

The process of selecting a steady state consists of taking a time period of 15 min, with a sample period of $1 \mathrm{~s}$, in which the measured parameters were within a fluctuation range lower than $1 \%$ on each variable. Once a steady state was achieved (with 900 direct measurements), the data used as a steady-state test is obtained averaging over a time period of 10 min (600 measurements).

\subsection{Data management}

For the analysis of the experimental data obtained during steady-state tests various equations have been used.

The thermal power removed by the working fluid at the evaporator is obtained as the product of the working fluid mass flow rate and the enthalpy difference between the evaporator inlet and outlet, as shown in Eq. 1. Similarly, the thermal power supplied by the working fluid at the condenser is obtained through Eq. 2.

$$
\begin{aligned}
& \dot{Q}_{w f, \text { evap }}=\dot{m}\left(h_{\text {evap }, o}-h_{\text {evap }, i}\right) \\
& \dot{Q}_{w f, \text { cond }}=\dot{m}\left(h_{\text {cond }, i}-h_{\text {cond }, o}\right)
\end{aligned}
$$

The net electrical power output is calculated using Eq. 3 from the measured electrical power generated by the expander and the measured electrical power consumed by the pump. The net electrical efficiency of the system is obtained through Eq. 4.

$$
\begin{gathered}
\dot{W}_{n}=\dot{W}_{e x p}-\dot{W}_{p p} \\
\eta_{n}=\frac{\dot{W}_{n}}{\dot{Q}_{w f, e v a p}}
\end{gathered}
$$

Regarding to the expander, various performance ratios are addressed. The isentropic efficiency is obtained through Eq. 5 as the ratio between the enthalpy difference in the real expansion process and the isentropic enthalpy difference in the ideal expansion process. The relationship between the measured electrical power generated by the expander and the maximum that could be ideally obtained in an isentropic expansion process is defined as the overall efficiency, by Eq. 6 . The volumetric performance of the expander is represented as the ratio between the calculated volumetric flow rate and the theoretically displaced by the expander, named filling factor [23], by Eq. 7. Other parameters calculated and used for the analysis are the pressure ratio in the expander, defined by Eq. 8, and the volume ratio in the expander, defined by Eq. 9 .

$$
\varepsilon_{i s}=\frac{h_{\text {exp }, i}-h_{\text {exp }, o}}{h_{\text {exp }, i}-h_{\text {exp }, o, i s}}
$$




$$
\begin{gathered}
\varepsilon_{o v}=\frac{\dot{W}_{\text {exp }}}{\dot{m}\left(h_{\text {exp }, i}-h_{\text {exp },, i s}\right)} \\
\varphi=\frac{\dot{m} v_{\text {exp }, i} 3600}{\dot{V}_{\text {exp }, i, i n}} \\
r_{p}=\frac{P_{\text {exp }, i}}{P_{\text {exp }, o}} \\
r_{v}=\frac{v_{\text {exp }, o}}{v_{\text {exp }, i}}
\end{gathered}
$$

\subsection{Propagation of errors in the estimated parameters}

To have a general understanding on the associated uncertainty with the parameters calculated from measurements, the characteristic parameters uncertainty propagation is obtained using the RSS method [22], shown in Table 4.

Table 4. Uncertainties for calculated parameters.

\subsection{Data validation}

In order to check the accuracy of the measurements, a comparison between the thermal power removed by the working fluid and the thermal power supplied by the thermal oil at the evaporator is carried out. In the same way, a comparison between the thermal power supplied by the working fluid and the thermal power removed by the water at the condenser is carried out. Both energy balances are presented in Fig. 3.

Fig. 3. Data validation comparing working fluid and secondary fluids thermal power at the evaporator and condenser.

The thermal power supplied by the thermal oil at the evaporator is obtained through Eq. 10 using the thermal oil volumetric flow rate, the temperatures at the evaporator inlet and outlet and the thermal oil properties at the operating conditions. Similarly, the thermal power removed by the water at the condenser is obtained through Eq. 11.

$$
\begin{gathered}
\dot{Q}_{\text {oil }, \text { evap }}=\dot{V}_{\text {oil }} \rho c_{p}\left(T_{\text {oil }, i}-T_{\text {oil }, o}\right) \\
\dot{Q}_{w, \text { cond }}=\dot{V}_{w} \rho c_{p}\left(T_{w, o}-T_{w, i}\right)
\end{gathered}
$$

\section{Results and discussion}


From the experimental data obtained during tests an analysis has been conducted, whose results are exposed and discussed in this section.

Fig. 4a shows that the mass flow rate of the working fluid of the ORC increases with the thermal oil inlet temperature and it is related with the density at the expander inlet, presented in Fig. 4b, due to the constant superheating at the volumetric expander inlet. Density at the expander inlet and mass flow rate are approximately $20 \%$ lower for HCFO-1233zd-E than for HFC-245fa. There is no significant difference in the evaporating temperatures for both working fluids, as can be appreciated in Fig. 4c. However, condensing temperatures are slightly lower for HCFO-1233zd-E than for HFC-245fa, as can be shown in Fig. 4d, due to the different mass flow rates through the condenser. As expected, evaporating temperatures are related with the thermal oil inlet temperatures, while condensing temperatures are related with the water inlet temperatures.

Fig. 4. (a) Mass flow rate, (b) density at expander inlet, (c) evaporating temperature and (d) condensing temperature.

Due to the different mass flow rates of the working fluids, thermal and electrical powers presented in Fig. 5 are higher for HFC-245fa than for HCFO-1233zd-E. So, thermal power input presented in Fig. 5a ranges from $8400 \mathrm{~W}$ to $12000 \mathrm{~W}$ for HFC-245fa and from $6900 \mathrm{~W}$ to $9900 \mathrm{~W}$ for HCFO-1233zd-E. Thermal power input increases with the thermal oil inlet temperature and lightly decreases with the water inlet temperature. Similar trend is observed for the thermal power output, as can be shown in Fig. 5b. Fig. $5 \mathrm{c}$ shows the electrical power generated by the expander for both working fluids. Maximum electrical power generated by the expander is $1340 \mathrm{~W}$ for HFC-245fa and $1175 \mathrm{~W}$ for HCFO-12233zd-E. As expected, electrical power generated by the expander is higher for high thermal oil inlet temperatures and low water inlet temperatures. The electrical power consumed by the pump, presented in Fig. 5d, increases with the thermal oil inlet temperature. Fig. 5e shows the net electrical power output that achieves a maximum value of $1090 \mathrm{~W}$ for HFC-245fa and 960W for HCFO-1233zd-E. The net electrical efficiency is similar for both working fluids, as can be shown in Fig. 5f. As expected, it increases with the thermal oil inlet temperature and decreases with the water inlet temperature, ranging from $5 \%$ to $9.7 \%$.

Fig. 5. (a) Thermal power input, (b) thermal power output, (c) electrical power generated by the expander, (d) electrical power consumed by the pump, (e) net electrical power output and (f) net electrical efficiency.

Regarding the expander performance, Fig. 6 shows its performance indicators. Fig. $6 \mathrm{a}$ presents the volume ratio of the working fluid through the expander, similar for both working fluids, that ranges between 5 and 9 . The volumetric performance of the expander is analyzed by means of the filling factor, with values around 1.375 for both working fluids, as can be shown in Fig. 6b. The isentropic performance is presented in Fig. 6c, with a maximum value of $75 \%$. HCFO-1233zd-E presents higher values of isentropic efficiency than HFC-245fa. This could be due to the lower pressure losses on 
the expander ports for HCFO-1233zd-E as it works with lower mass flow rates. Fig. 6d shows the overall efficiency of the expander, similar for both working fluids, ranging from $44 \%$ to $57 \%$.

Fig. 6. (a) Volume ratio, (b) filling factor, (c) isentropic efficiency and (d) overall efficiency.

\section{Conclusions}

This work has conducted an experimental evaluation of the working fluid HCFO1233zd-E as HFC-245fa replacement in ORC systems for low temperature heat sources. For this, an ORC module has been tested with both working fluids and different operating conditions, simulating a low temperature heat source with inlet temperatures varying from about $140^{\circ} \mathrm{C}$ to more than $155^{\circ} \mathrm{C}$. So, 160 steady-state tests have been achieved and analyzed.

Due to the different densities of the working fluids, the mass flow rate for HCFO$1233 z d-E$ is approximately $20 \%$ lower than for HFC-245fa. This causes thermal and electrical powers to be lower for HCFO-1233zd-E than for HFC-245fa. So, thermal power input presents a maximum value of $12000 \mathrm{~W}$ for HFC-245fa and $9900 \mathrm{~W}$ for HCFO-1233zd-E. Similarly, net electrical power output presents a maximum value of $1090 \mathrm{~W}$ for HFC-245fa and 960W for HCFO-1233zd-E. However, net electrical efficiency is similar for both working fluids ranging from $5 \%$ to $9.7 \%$.

Regarding the expander performance, various performance indicators are addressed. The volumetric performance of the expander is analyzed by means of the filling factor, with values around 1.375 for both working fluids. The isentropic performance has a maximum value of $75 \%$. HCFO-1233zd-E presents higher values of isentropic efficiency than HFC-245fa. This could be due to the lower pressure losses on the expander ports for HCFO-1233zd-E as it works with lower mass flow rates. The overall efficiency of the expander, similar for both working fluids, ranges from $44 \%$ to $57 \%$.

\section{Acknowledgements}

The authors thankfully acknowledge the cooperation of Rank® for its support in this project.

\section{References}

[1] B. Peris, J. Navarro-Esbrí, F. Molés, M. González-Piquer, A. Mota-Babiloni, Experimental characterization of an Organic Rankine Cycle (ORC) for power and Combined Heat and Power (CHP) applications from low grade heat sources, Energy.

[2] J. Wang, Y. Dai, L. Gao, Exergy analyses and parametric optimizations for different cogeneration power plants in cement industry, Applied Energy 86 (2006) 941 - 948. 
[3] J.S. Meacher, Organic Rankine Cycle systems for waste heat recovery in refineries and chemical process plants, in: ESL-IE-81-04-90, Proceedings from the 3rd Industrial Energy Technology Conference, Houston, TX, 1981.

[4] B. Peris, J. Navarro-Esbrí, F. Molés, Bottoming organic Rankine cycle configurations to increase Internal Combustion Engines power output from cooling water waste heat recovery, Applied Thermal Engineering 61 (2013) 364 - 371.

[5] M. Wang, J. Wang, Y. Zhao, P. Zhao, Y. Dai, Thermodynamic analysis and optimization of a solar-driven regenerative organic Rankine cycle (ORC) based on flatplate solar collectors, Applied Thermal Engineering 50 (2013) 816 - 825.

[6] M. Tanczuk, R. Ulbrich, Implementation of a biomass-fired co-generation plant supplied with an ORC (Organic Rankine Cycle) as a heat source for small scale heat distribution system - A comparative analysis under Polish and German conditions, Energy 62 (2013) $132-141$.

[7] H. Zhai, L. Shi, Q. An, Influence of working fluid properties on system performance and screen evaluation indicators for geothermal ORC (organic Rankine cycle) system, Energy 74 (2014) 2 - 11.

[8] B. Saleh, G. Koglbauer, M. Wendland, J. Fischer, Working fluids for lowtemperature organic Rankine cycles, Energy 32 (2007) 1210 - 1221.

[9] Z. Shengjun, W. Huaixin, G. Tao, Performance comparison and parametric optimization of subcritical Organic Rankine Cycle (ORC) and transcritical power cycle system for low-temperature geothermal power generation, Applied Energy 88 (2011) $2740-2754$.

[10] S. Quoilin, M. Van Den Broek, S. Declaye, P. Dewallef, V. Lemort, Technoeconomic survey of Organic Rankine Cycle (ORC) systems, Renewable and Sustainable Energy Reviews 22 (2013) 168 - 186.

[11] B. Peris, J. Navarro-Esbrí, F. Molés, R. Collado, A. Mota-Babiloni, Performance evaluation of an Organic Rankine Cycle (ORC) for power applications from low grade heat sources, Applied Thermal Engineering 75 (2014) 763 - 769.

[12] R. Bracco, S. Clemente, D. Micheli, M. Reini, Experimental tests and modelization of a domestic-scale ORC (Organic Rankine Cycle), Energy 58 (2013) 107 - 116.

[13] S. Declaye, S. Quoilin, L. Guillaume, V. Lemort, Experimental study on an opendrive scroll expander integrated into an ORC (Organic Rankine Cycle) system with R245fa as working fluid, Energy 55 (2013) 173 - 183.

[14] B. Peris, J. Navarro-Esbrí, F. Molés, J.P. Martí, A. Mota-Babiloni, Experimental characterization of an Organic Rankine Cycle (ORC) for micro-scale CHP applications, Applied Thermal Engineering (2015).

[15] Kyoto Protocol, Report of the Conference of the Parties, United Nations Framework Convention on Climate Change (UNFCCC), 1997. 
[16] G. Myhre, D. Shindell, F.M. Bréon, W. Collins, J. Fuglestvedt, J. Huang, D. Koch, J.F. Lamarque, D. Lee, B. Mendoza, T. Nakajima, A. Robock, G. Stephens, T. Takemura and H. Zhang, 2013: "Anthropogenic and Natural Radiative Forcing", In: Climate Change: The Physical Science Basis. Contribution of Working Group I to the Fifth Assessment Report of the Intergovernmental Panel on Climate Change [T.F. Stocker, D. Qin, G.K. Plattner, M. Tignor, S.K. Allen, J. Boschung, A. Nauels, Y. Xia, V. Bex and P.M. Midgley (eds.)], Cambridge University Press, Cambridge, United Kingdom and New York, NY, USA.

[17] G. Zyhowski, A. Brown, Low Global Warming Fluids for Replacement of HFC245fa and HFC-134a in ORC Applications, ORC 2011 Delft Presentation, 2011.

[18] K.O. Patten, D.J. Wuebbles, Atmospheric lifetimes and ozone depletion potentials of trans-1-chloro-3,3,3-trifluoropropylene and trans-1,2-dichloroethylene in a threedimensional model, Atmos. Chem. Phys. Discuss., 10, 16637-16657, 2010.

[19] F. Molés, J. Navarro-Esbrí, B. Peris, A. Mota-Babiloni, A. Barragán-Cervera, K. Kontomaris, Low GWP alternatives to HFC-245fa in Organic Rankine Cycles for low temperature heat recovery: HCFO-1233zd-E and HFO-1336mzz-Z, Applied Thermal Engineering 71 (2014) $204-212$.

[20] Rank®, Castellón, Spain, www.rankweb.es [accessed 27.01.2015].

[21] E.W. Lemmon, M.L. Huber, M.O. McLinden, REFPROP, NIST Standard Reference Database 23, v.8, National Institute of Standards, Gaithersburg, MD, USA, 2007.

[22] J.R. Taylor, An introduction to error analysis, The study of uncertainties in physical measurements, University Science Books, Sausalito, USA, 1997.

[23] R. Zanelli, D. Favrat, Experimental investigation of a hermetic scroll expander generator, in: Proceedings of the International Compressor Engineering Conference at Purdue, 1994, 459 - 464. 


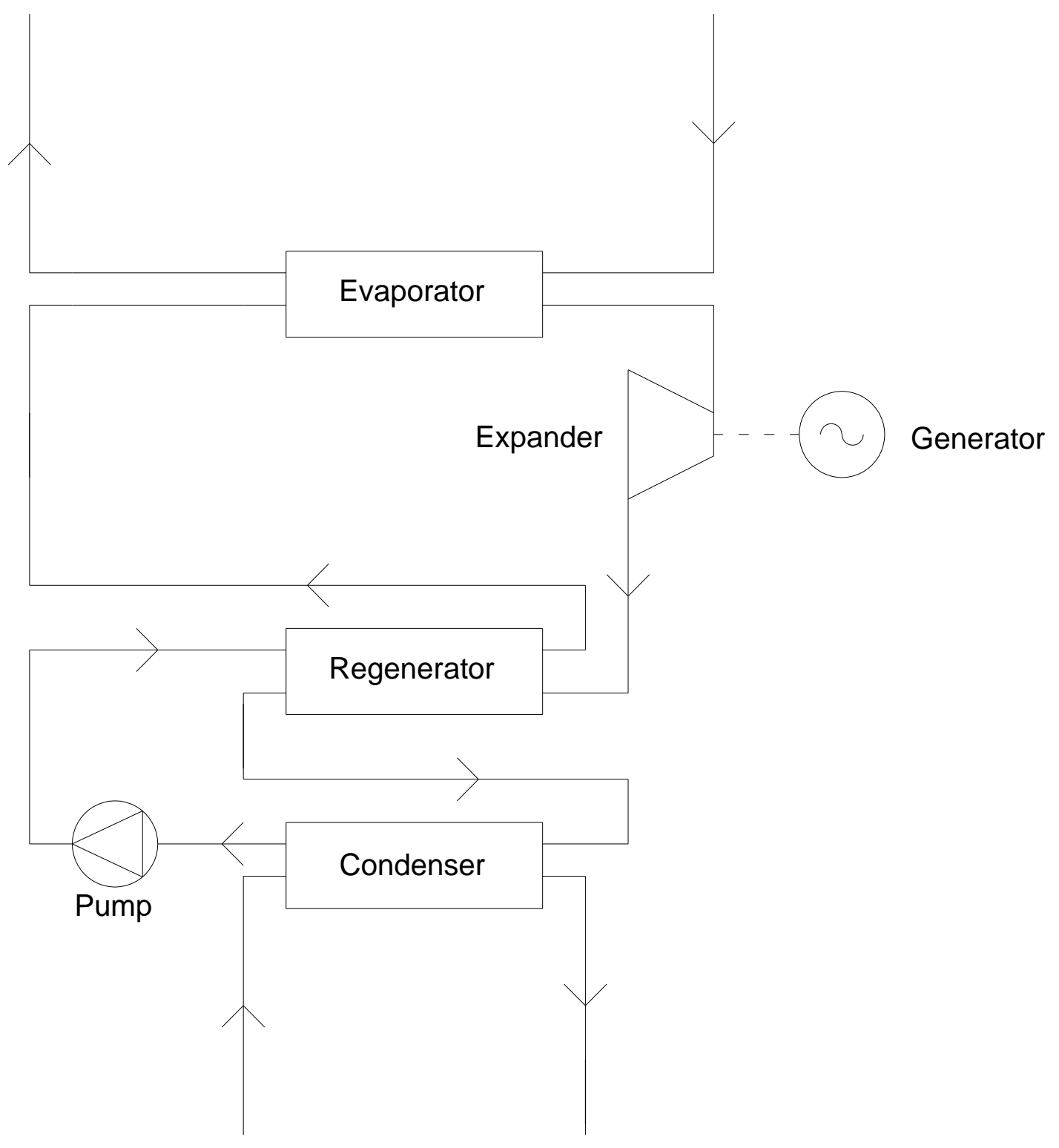

Fig. 1. Regenerative configuration. 
Working fluid/Water inlet temperature $\left({ }^{\circ} \mathrm{C}\right) \bullet \mathrm{HFC}-245 \mathrm{fa} / 25 \quad \Delta \mathrm{HFC}-245 \mathrm{fa} / 32.5 \quad \square \mathrm{HFC}-245 \mathrm{fa} / 40$

$\diamond \mathrm{HCFO}-1233 \mathrm{zd}-\mathrm{E} / 25 \quad \triangle \mathrm{HCFO}-1233 \mathrm{zd}-\mathrm{E} / 32.5 \mathrm{GCFO}-1233 \mathrm{zd}-\mathrm{H} / 40$

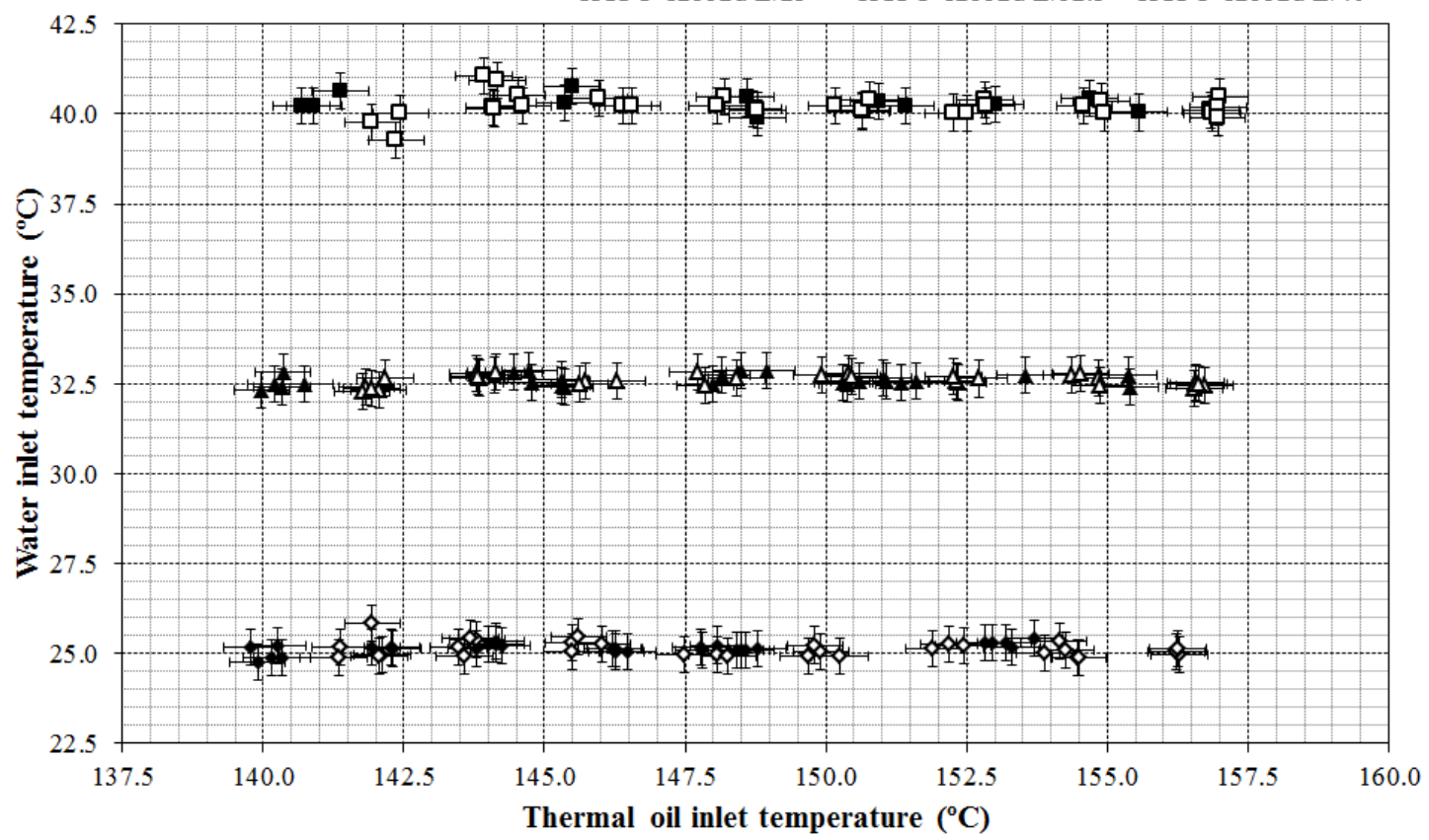

Fig. 2. Thermal oil and water inlet temperatures obtained during steady-state tests. 

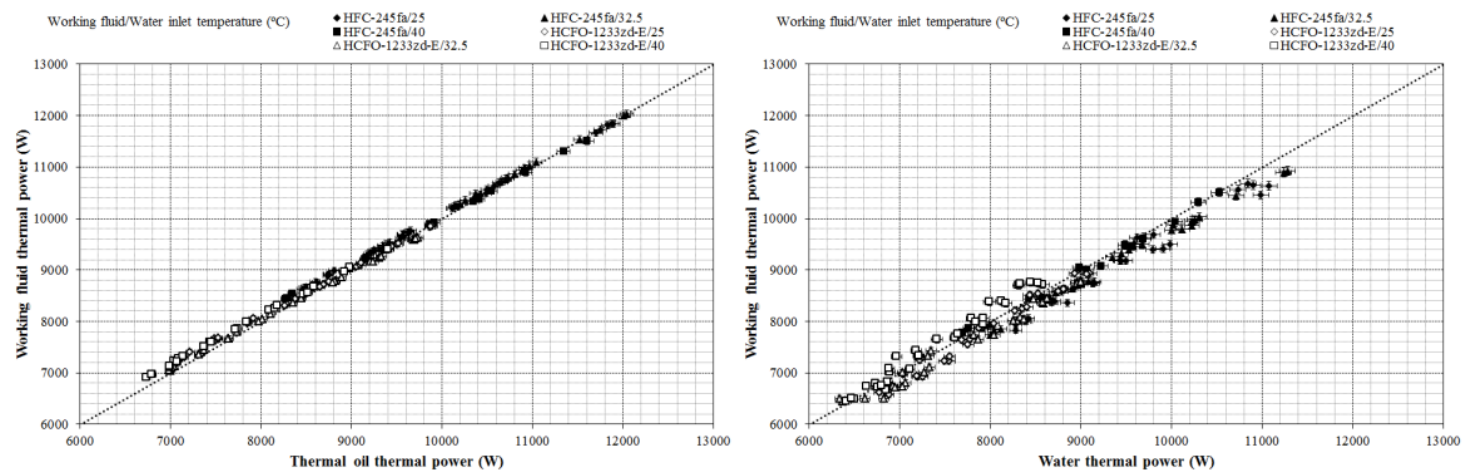

Fig. 3. Data validation comparing working fluid and secondary fluids thermal power at the evaporator and condenser. 


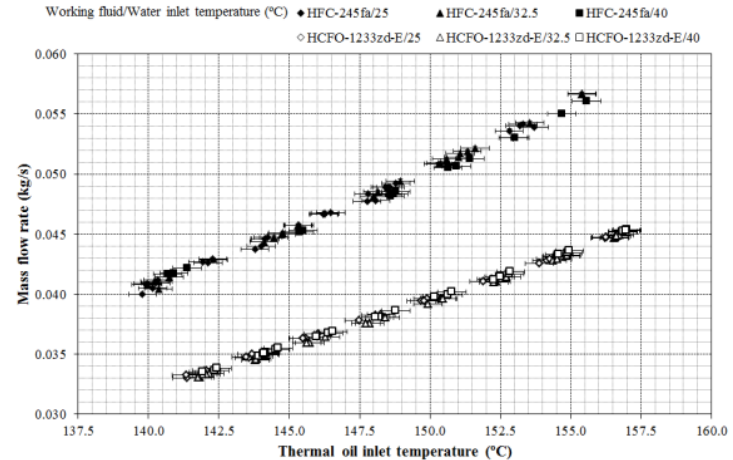

(a)

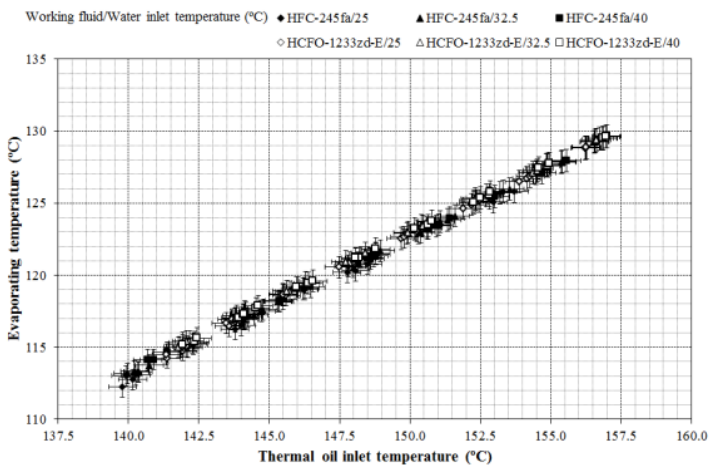

(c)

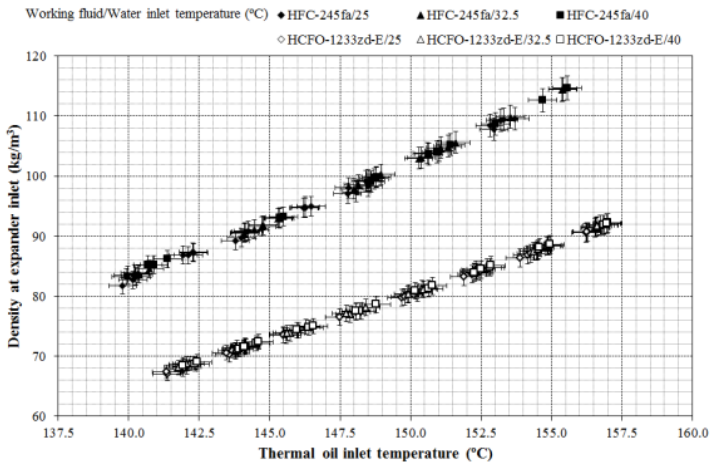

(b)

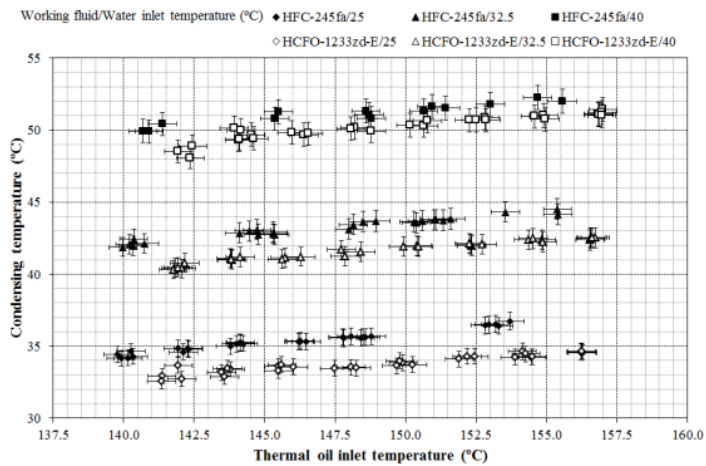

(d)

Fig. 4. (a) Mass flow rate, (b) density at expander inlet, (c) evaporating temperature and (d) condensing temperature. 


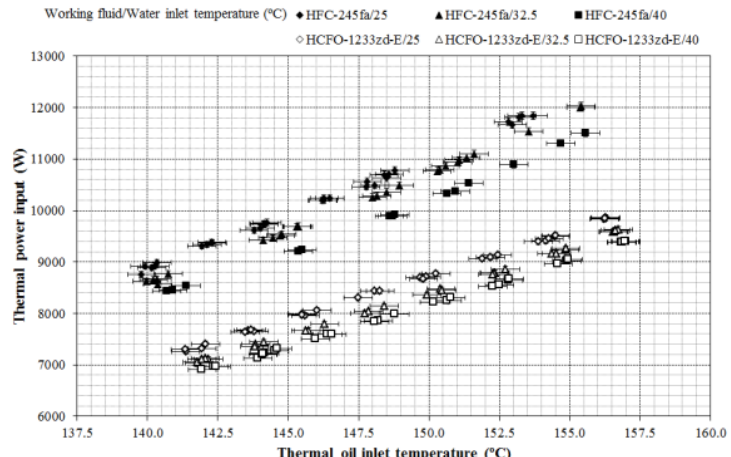

(a)

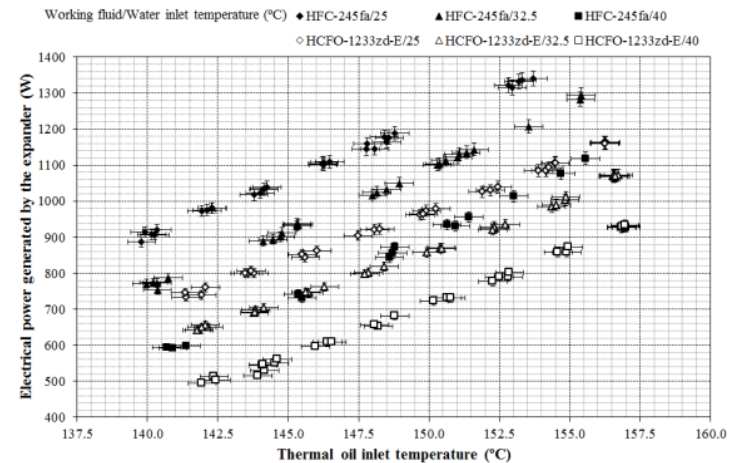

(c)

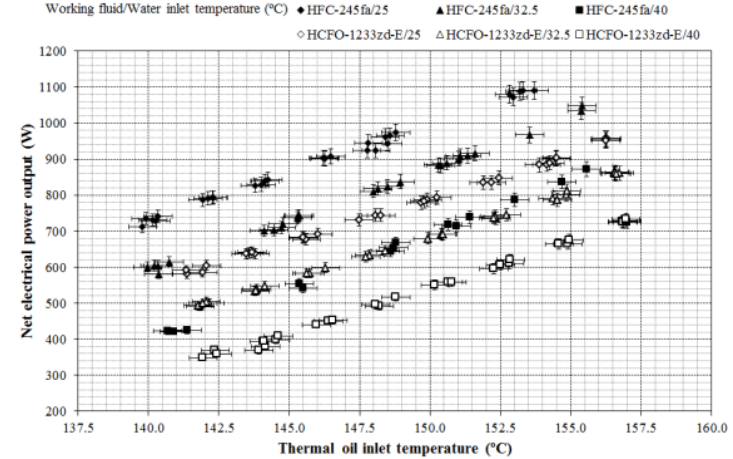

(e)

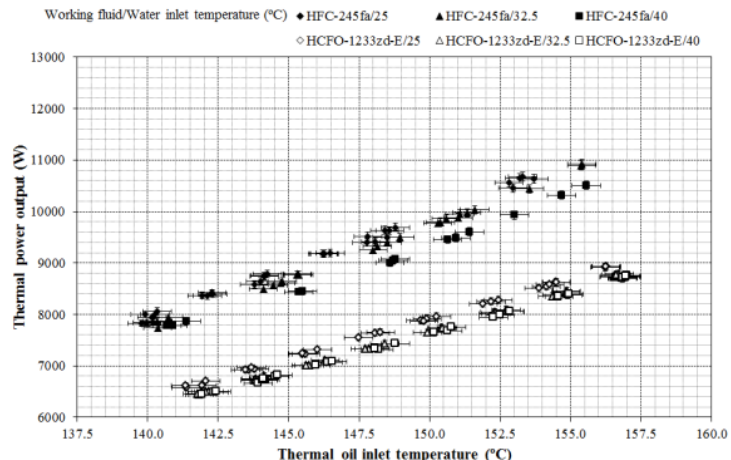

(b)

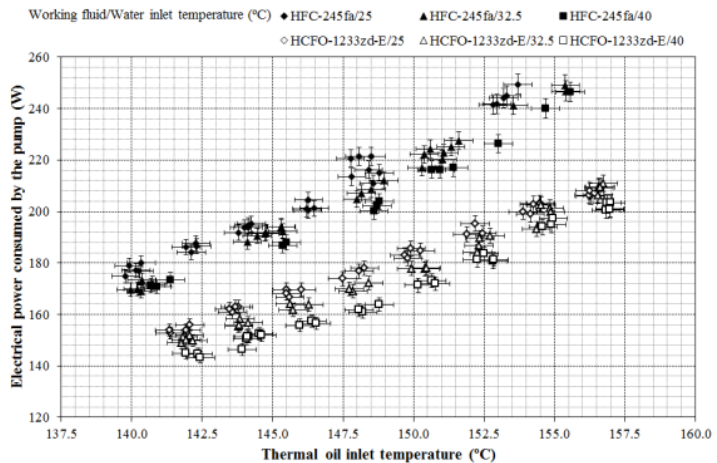

(d)

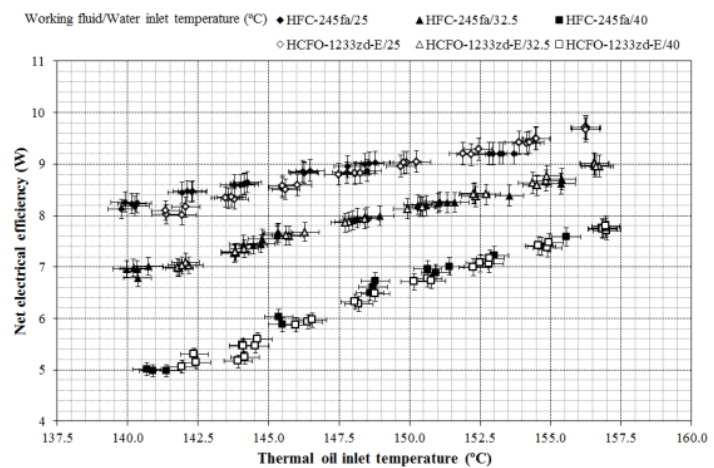

(f)

Fig. 5. (a) Thermal power input, (b) thermal power output, (c) electrical power generated by the expander, (d) electrical power consumed by the pump, (e) net electrical power output and (f) net electrical efficiency. 


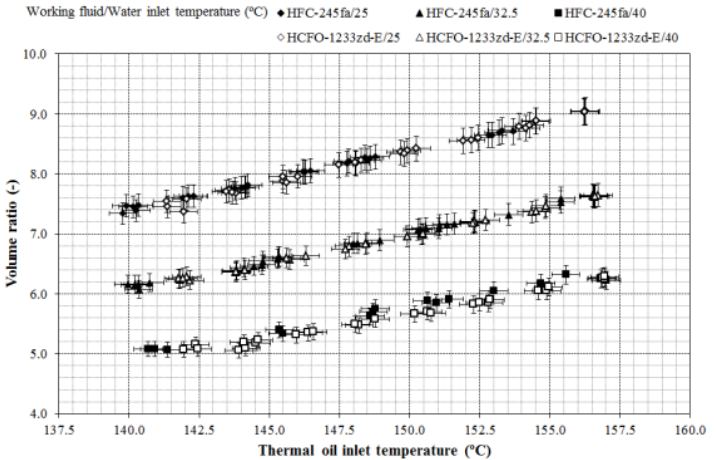

(a)

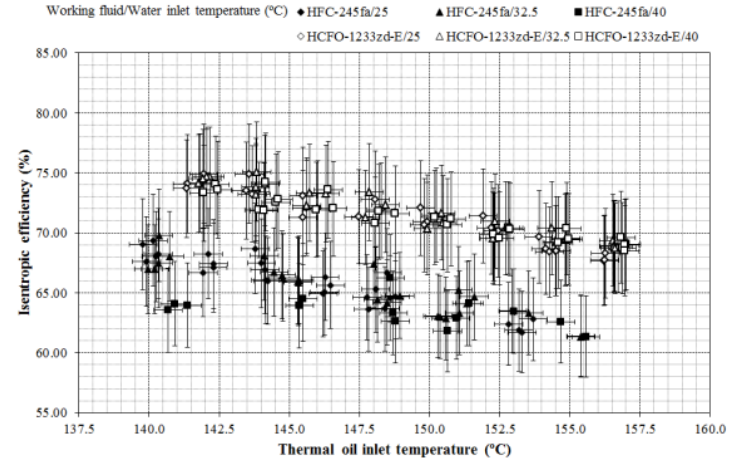

(c)

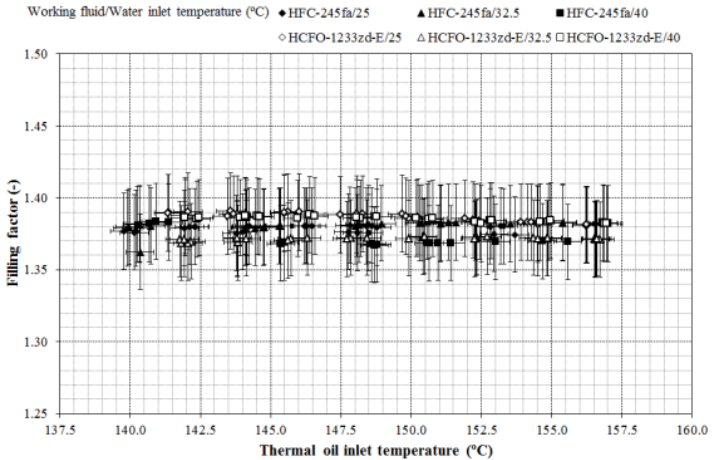

(b)

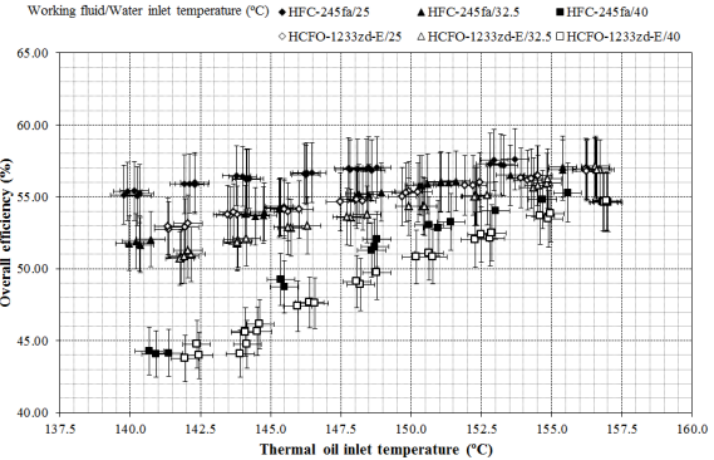

(d)

Fig. 6. (a) Volume ratio, (b) filling factor, (c) isentropic efficiency and (d) overall efficiency. 


\section{FIGURE CAPTIONS}

Fig. 1. Regenerative configuration.

Fig. 2. Thermal oil and water inlet temperatures obtained during steady-state tests.

Fig. 3. Data validation comparing working fluid and secondary fluids thermal power at the evaporator and condenser.

Fig. 4. (a) Mass flow rate, (b) density at expander inlet, (c) evaporating temperature and (d) condensing temperature.

Fig. 5. (a) Thermal power input, (b) thermal power output, (c) electrical power generated by the expander, (d) electrical power consumed by the pump, (e) net electrical power output and (f) net electrical efficiency.

Fig. 6. (a) Volume ratio, (b) filling factor, (c) isentropic efficiency and (d) overall efficiency. 
Table 1. Commercial ORC module features.

\begin{tabular}{ll}
\hline Alternator rated power $(\mathrm{kW})$ & 1.5 \\
ORC configuration & Regenerative \\
Working fluid & HFC-245fa \\
Expander technology & Volumetric \\
Heat exchangers type & Brazed plate \\
Maximum thermal oil inlet temperature $\left({ }^{\circ} \mathrm{C}\right)$ & 160 \\
Maximum water inlet temperature $\left({ }^{\circ} \mathrm{C}\right)$ & 45 \\
\hline
\end{tabular}


Table 2. Measured parameters and equipment uncertainty.

\begin{tabular}{lll}
\hline Measured parameter & Sensor & Uncertainty \\
\hline Temperatures & K-type thermocouples & $\pm 0.5{ }^{\circ} \mathrm{C}$ \\
Pressures & Piezoelectric pressure transducers & $\pm 0.5 \mathrm{kPa}$ \\
Working fluid mass flow rate & Coriolis mass flow meter & $\pm 0.3 \%$ \\
Electrical power & Digital wattmeter & $\pm 1.55 \%$ \\
Thermal oil volumetric flow rate & Vortex flow meter & $\pm 0.028 \mathrm{~m}^{3} / \mathrm{h}$ \\
Water volumetric flow rate & Electromagnetic flow meter & $\pm 0.5 \%$ \\
\hline
\end{tabular}


Table 3. Range of operating conditions in the experimental steady-state tests.

\begin{tabular}{ll}
\hline Parameter & Range \\
\hline$T_{o i l, i}\left({ }^{\circ} \mathrm{C}\right)$ & $139.79-157.01$ \\
$T_{o i l, o}\left({ }^{\circ} \mathrm{C}\right)$ & $126.73-143.21$ \\
$\dot{V}_{o i l}\left(\mathrm{~m}^{3} / \mathrm{h}\right)$ & $1.29-1.30$ \\
$T_{w, i}\left({ }^{\circ} \mathrm{C}\right)$ & $24.76-41.06$ \\
$T_{w, o}\left({ }^{\circ} \mathrm{C}\right)$ & $26.62-43.03$ \\
$\dot{V}_{w}\left(\mathrm{~m}^{3} / \mathrm{h}\right)$ & $3.40-3.46$ \\
\hline
\end{tabular}


Table 4. Uncertainties for calculated parameters.

\begin{tabular}{ll} 
Calculated parameter & Uncertainty \\
\hline$\rho_{\text {exp }, i}$ & $\pm 1.72 \%$ \\
$T_{\text {evap }}$ & $\pm 0.62 \%$ \\
$T_{\text {cond }}$ & $\pm 1.61 \%$ \\
$\dot{Q}_{i}$ & $\pm 0.61 \%$ \\
$\dot{Q}_{o}$ & $\pm 0.80 \%$ \\
$\dot{W}_{n}$ & $\pm 2.29 \%$ \\
$\eta_{n}$ & $\pm 2.35 \%$ \\
$r_{p}$ & $\pm 2.08 \%$ \\
$r_{v}$ & $\pm 2.46 \%$ \\
$\varphi$ & $\pm 1.91 \%$ \\
$\varepsilon_{i s}$ & $\pm 5.51 \%$ \\
$\varepsilon_{o v}$ & $\pm 3.69 \%$ \\
\hline
\end{tabular}

